\title{
A review of some tick-borne pathogens of dogs
}

\author{
Ogbu, K. I. ${ }^{*}$, Olaolu, O. S. ${ }^{2}$, Ochai, S..$^{3}$ and Tion, M. T. ${ }^{4}$ \\ ${ }^{1}$ Department of Animal Health, Federal College of Animal Health and Production Technology, National Veterinary \\ Research Institute Vom, Plateau State, Nigeria. \\ ${ }^{2}$ Department of Veterinary Microbiology, Faculty of Veterinary Medicine, Ahmadu Bello University, Zaria, Kaduna State, \\ Nigeria. \\ ${ }^{3}$ Faculty of Veterinary medicine, University of Maiduguri, Borno state, Nigeria. \\ ${ }^{4}$ Department of Veterinary Medicine, College of Veterinary Medicine, Federal University of Agriculture, Makurdi, Benue \\ State, Nigeria. \\ *Corresponding author. Email: kenike_mary@yahoo.com; drken2016@gmail.com. Tel: +2348030852357.
}

Copyright $@ 2018$ Ogbu et al. This article remains permanently open access under the terms of the Creative Commons Attribution License 4.0, which permits unrestricted use, distribution, and reproduction in any medium, provided the original work is properly cited.

Received 6th July, 2018; Accepted 8th August, 2018

\begin{abstract}
Ticks and tick-borne diseases have great economic and medical importance worldwide and they affect both animal and human health by sucking blood and also transmitting protozoan, bacterial, rickettsial, spirochetal and viral agents. Ticks can live in all regions of the world except Polar Regions. Tick-borne encephalitis Virus, Babesiosis, Anaplasmosis, Ehrlichiosis, and Hepatozoonosis are important tick-borne diseases of dogs and they influence a great variety of other domestic and wild animals. Ticks are ectoparasites of mammals, birds and reptiles specializing as obligate blood sucking permanent ectoparasitic arthropods. As vector of important haemoparasitic disease, tick surpasses all other arthropods, apart from mosquitoes as diseases agents of humans and lead to poor performance of the animals. One or more of the approximately 840 known species of ticks are found in most terrestrial regions of the earth. Two major families of ticks are ixodidae (hard bodies ticks) and argasidae (soft bodies ticks), with ixodidae being the largest and most important family. These vectors such as Rhipicephalus sanguineus and Ixodes ricinus which are endemic in Nigeria, have affected the performance of dogs which are major human companions through their activities such as blood sucking, disease transmission, biting effect and causing listlessness through itching and scratching. The important pathogens dealt with in this study, include tick-borne encephalitis virus, Ehrlicia canis, Anaplasma phagocytophilum, Hepatozoon canis and Babesia canis. This review aims at to create better awareness on ticks and tick-borne pathogens of dogs providing latest knowledge on prevention and control of this menace.
\end{abstract}

Key words: Dogs and tick vectors, Encephalitis virus, epidemiology and harmful effects, Haemoparasites, molecular detection, preventive measures, Rickettsiae,

\section{INTRODUCTION}

Ticks are the second most common blood-feeding parasites after mosquitoes. They do not only destroy blood cells thereby causing anaemia but also transmit and carry different kinds of protozoa, viruses and bacteria some of which may cause tick-borne diseases (TBDs).(de la Fuente et al., 2008; Otranto et al., 2014). These tick-borne diseases not only include various existing infectious diseases, but also comprise of both emerging and reemerging infectious diseases. An instance of such emerging infectious disease is fever characterized by thrombocytopaenia, this was reported in China and was seen to be endemic and it poses a serious threat to both animal and human health (Parola et al., 2005; Yu et al., 2011). However, in the last few decades, the number of reported cases of infection with new TBDs in humans and animals has increased (Kernif et al., 2016).

Transmission of tick-borne pathogens occurs from tick to their hosts but both trans-ovarianlly (i.e. the eggs acquire infection from the egg-laying female) and trans-stadially (i.e. both larvae and nymphs are able to transmit the pathogen to the next developmental stage) (Beugnet, 2002). Attaching of ticks firmly to their hosts, facilitates the 
effective blood feeding, the transmission of pathogens but also the spread of both ticks and microorganisms to different geographical habitats via migrating animals or travelling pets (Kenny et al., 2004b).

Owing to the fact that some TBDs in humans are zoonoses and are of grave economic and medical importance, it is necessary to expatiate more on the tickborne pathogens in pets particularly of dogs.

The most common tick-borne protozoan pathogens of dogs are Babesia and Hepatozoon (Homer et al., 2000; Baneth et al., 2003). These haemoparasites live in mammalian blood cells and cause severe diseases and sometimes death in infected animals (Schnittger et al., 2012). Specifically, Babesia gibsoni, Babesia canis, Babesia rossi, and Babesia vogeli are causative agents of canine babesiosis (biliary fever). B. gibsoni is distributed in Asia, North America, Europe, and northern and eastern Africa (Farwell et al., 1982; Jefferies et al., 2003; Lobetti, 1998). B. canis is transmitted by Dermacentor reticulatus, which is prevalent in Europe (Solano-Gallego and Baneth, 2011). The other two species, B. rossi and B. vogeli, are mainly transmitted by Haemaphysalis leachi and Rhipicephalus sanguineus sensu lato (s.l.), respectively (Apanaskevich et al., 2007; Criado-Fornelio et al., 2003). The distribution of $B$. rossi is restricted to sub-Saharan Africa, while that of $B$. vogeli is worldwide (Europe, Africa, Asia, South and North America) (Oyamada et al., 2005; Matjila et al., 2008). Hepatozoon canis and Hepatozoon americanum are the agents of canine hepatozoonoses that range from being asymptomatic with low levels of parasitaemia to a severe life-threatening illness characterised by high levels of parasitaemia, fever, anaemia, and lethargy (Baneth et al., 2000; Baneth et al., 2003). These two Hepatozoon species are genetically and geographically distinct (Baneth et al., 2000). Hepatozoon canis is an apicomplexan protozoon. Its transmission differs from other tick-borne pathogens because infection of the dog takes place by ingestion of a tick containing the parasite. Its vector species is $R$. sanguineus. $H$. canis is distributed in Africa, southern Europe, the Middle East, and Asia (Baneth and Vincent-Johnson, 2006) and is mainly transmitted by $R$. sanguineus s.l. and Haemaphysalis longicornis (Dantas-Torres et al., 2012; Murata et al., 1995). $H$. americanum is found in the Americas and is transmitted by Amblyomma maculatum (Mathew et al., 1998). Recently, new Hepatozoon spp. were reported in dogs and wildlife in Turkey and Brazil (Aydin et al., 2015; Soares et al., 2017).

Anaplasma and Ehrlichia species are obligate intracellular bacteria that belong to the family of Anaplasmataceae. These tick-borne pathogens infect humans and animals all over the world. Anaplasma platys is primarily found in dogs with cyclic thrombocytopaenia (Harvey et al., 1978). In addition, new Anaplasma species that are closely related to Anaplasma phagocytophilum, which causes human granulocytic anaplasmosis, have been detected in canine blood (Inokuma et al., 2005).
Ehrlichia canis is the causative agent of canine ehrlichiosis, which is transmitted by $R$. sanguineus s.l. (Groves et al., 1975; Aguiar et al., 2007). While E. canis was initially thought to be pathogenic in canines only, it was eventually also detected in human patients with the typical clinical findings of ehrlichiosis (Perez et al., 2006).

Tick-borne encephalitis virus (TBEV) (Flaviviridae) is primary pathogenic to humans but also infects dogs (Shaw et al., 2001). Seroprevalence of the virus has been found to be higher in dogs because they come into contact with the infected vector ticks (mainly Ixodes. ricinus) more frequently than humans. However, the risk for developing clinical tick-borne encephalitis (TBE) in tick-infested dogs in an endemic area seems to be rather small for unknown reasons. Altogether less than twenty clinical TBE infections of dogs have been reported in Austria, Germany, Sweden and Switzerland (Beugnet, 2002).

Therefore, the aim of this review is to help create a better awareness on ticks and tick-borne pathogens of dogs by providing latest knowledge of the pathogens, prevention and control of this menace.

\section{CANINE EHRLICHIOSIS}

Ehrlichiosis is also known as canine rickettsiosis, canine hemorrhagic fever, canine typhus, tracker dog disease, and tropical canine pancytopenia (spelling) is a tick-borne disease of dogs usually caused by the organism, Ehrlichia canis. Humans can become infected by $E$. canis and other species after tick exposure.

\section{Etiology}

Ehrlichia is a Rickettsia of the Anaplasmataceae family, Gram-negative intracytoplasmic bacteria that invade and multiply within leukocytes and platelets in the peripheral blood of various species of domestic and wild mammals. It causes Ehrlichiosis (Borjesson, 2000), a world-wide distributed zoonosis (Perez et al., 2005), concentrated in tropical and subtropical regions due to the geographical distribution of its vector tick Ixodidae, $R$. sanguineus which can rarely infect humans (Dantas-Torres et al., 2006). In Brazil, this seems to be the main vector for $E$. canis in urban areas, although in rural areas human infection seems to be related to the genus Amblyomma (Labruna and Pereira, 2001).

Several species of Ehrlichia infect dogs such as Anaplasma platys, E. equi, E. ewingii, E. risticii, $E$. chaffeensis, E. sennetsu and $E$. canis. The latter being the main species that infects dogs producing several clinical symptoms (Stiles, 2000) - fever, anorexia, vomiting, loss of weight, enlargement of the liver, spleen and lymph nodes, epistaxis, hemorrhage and thrombocytopenia (Moreira et al., 2003). 


\section{Transmission Cycle}

The brown dog tick ( $R$. sanguineus) acts as the primary vector of $E$. canis transferring the pathogen between hosts during blood meal. Dogs both domestic and wild serve as reservoir hosts for this pathogen and are the primary hosts of brown dog ticks. Brown dog ticks become carriers of the pathogen when they take a blood meal from a rickessemic dog. Stored in midgut and salivary gland of an infected tick, $E$ canis is transferred via the saliva of ticks carrying the pathogen to host during blood meal (Bowman et al., 2009). If infected while in the larval stage, the ticks retains the pathogen through the next two life instars and can inoculate hosts during blood meals in both the nymph and adult stage in transstadial transmission. Because of the vector of $E$. canis uses canine species as a primary hosts, this organism is most commonly associated with dogs, but human cases have been reported.

\section{Epidemiology}

Serologic evidence of previous studies around the world indicated that $E$. canis is present among dogs throughout all continents with a prevalence ranging from 30 to $80 \%$ in some countries of Africa (Azzag et al., 2015; Inokuma et al., 2006; Kelly et al., 2004; Ndip et al., 2005; Davoust et al., 2006), while in some Asian countries it was 0.2 to $30 \%$ (Inokuma et al., 1999; Stich et al., 2008). In Europe, a prevalence ranging from 2 to $50 \%$ have been found. A study realized in the USA detected most often Ehrlichia antibodies in dogs in the Southeast, with $1.3 \%$ of samples testing positive, whereas other regions showed lower numbers ranging from 0.3 to $0.6 \%$. (Bowman et al., 2009). Depending on technique used, different results were found in Oklahoma, where the prevalence of $E$. canis was $10.8 \%$ by serology, and $3.1 \%$ by the polymerase chain reaction (PCR) (Murphy et al., 1998). Among dogs belonging to the U.S.A. military forces, seropositivity to $E$. canis ranged from $8 \%$ in cold zones (above $45^{\circ}$ latitude) to $24 \%$ in temperate places (between 40 and $45^{\circ}$ latitude); a $13 \%$ prevalence was found in tropical zones (below $40^{\circ}$ latitude) (Keefe et al., 1982). Several studies on E. canis prevalence have been realized in Brazil. In Grenade, $43.8 \%$ of dogs tested were positive for E. canis (Yabsley et al., 2008) while in Mexico, studies performed in the southern area found $44 \%$ of seropositive dogs to $E$. canis with ELISA testing (Rodriguez-Vivaz et al., 2005). Although much have been said about the presence of this disease in Mexico, currently there are no reports of it in the northeast region; therefore, the goal of the present study was to estimate the seroprevalence of ehrlichiosis in dogs from the city of Monterrey, located in this part of Mexico.

\section{Clinical signs}

There are three stages of erhrlichiosis:

\section{Acute stage}

Symptoms present around 1-3 weeks after bite from infected tick. Enlarged lymph nodes, weakness, lethargy, depression, lack of appetite, difficult respiration and limb edema.

\section{Sub-clinical stage}

The organism may be present from months or years without clinical symptoms.

\section{Chronic stage}

Abnormal bleeding, nose bleeding, severe weight loss, fever, difficulty in breathing due to inflammation of the lungs, joint inflammation and pain, seizures in some animals, lack of coordination, head tilt, anemia, kidney failure and paralysis.

\section{Pathology}

Studies have shown that partial feeding of nymphs infected as (tick) larvae with $E$. canis is one possibility for these ticks to be able to infect dogs. The $E$. canis organisms are found in the midgut and salivary glands of infected adult ticks. The tick can transfer the organism from its saliva to the dog while feeding. Once inside the dog, they infect monocytes capable of spreading throughout the lymphatic system, including the spleen and liver. This will lead to an abnormal increase in cell size and number, known as hyperplasia. Replication and cell division can lead to further spreading of the bacterium throughout the host and eventually leads to anaemia and an increase in platelet count. Once the dog is infected, several signs of ehrlichiosis include marked thrombocytopaenia, pyrexia, reduction in the packed cell volume and the presence of $E$. canis in peripheral blood mononuclear cells. If the infection is not treated, the disease can take on a chronic form, where bone marrow will fail to develop along with anaemia, making the dog more susceptible to other infections. The dog will respond poorly to treatment at this stage and soon die of hemorrhage (Watanabe et al., 2004).

\section{Diagnosis}

Diagnosis is achieved most commonly by serologic testing of the blood for the presence of antibodies against the Ehrlichia organism. Many veterinarians routinely test for the disease, especially in enzootic area. During the acute phase of infection, the test can be falsely negative because the body will not have had time to make antibodies to the infection. As such, the test should be repeated. PCR test can be performed during this stage to detect genetic 
material of the bacteria. The PCR test is more likely to yield a negative result during the subclinical and chronic disease phases. In addition, blood test may show abnormalities in the numbers of red blood cells, white blood cells, and most commonly platelets, if the disease is present. Uncommonly, a diagnosis can be made by microscopical examination of blood smear for the presence of the Ehrlichia morulae, which sometimes can be seen as intracytoplasmic inclusion bodies within a white blood cell (Dumler et al., 2007).

\section{Treatment}

E. canis is commonly treated via chemoprophylaxis with antibiotic, doxycycline. If diagnosed before the clinical stage, E. canis is almost completely curable but prolonged presence of the pathogen leads to hemorrhage which usually results in the death of the patient (Bowman et al., 2009).

\section{ANAPLASMOSIS}

Granulocytic anaplasmosis is a tick-borne disease caused by Anaplasma phagocytophilum - a rickettsial pathogen, causing granulocytic blood infections in humans and animals (Alleman et al., 2008). The clinical appearance of A.phagocytophilum infection in dogs is defined in different ways: granulocytic ehrlichiosis (Bexfield et al., 2005) most commonly as anaplasmosis or granulocytic anaplasmosis.

\section{Etiology}

A. phagocytophilum is a Gram negative, obligate intracellular pleiomorphic agent. Up to 2001, $A$. phagocytophilum belonged to the genus Ehrlichia phagocytophila. This genus included E. phagocytophila (causative agent of the tick-borne fever in cattle, goats and sheep), Ehrlichia equi (causing granulocytic ehrlichiosis in horses) and an unnamed agent of human granulocytic ehrlichiosis (HGE) (Lillienook et al., 1998). On the basis of sequential analysis of $16 \mathrm{~S}$ rRNA and groESI operons, these three aetiological agents were united in one species and renamed to $A$. phagocytophilum. Target cells for $A$. phagocytophilum are neutrophil leukocytes and sometimes eosinophils (Pusterla et al., 1999). The earliest time when anaplasmae could be seen is 4 to 18 days after the infection as elementary bodies of 0 to $6 \mu \mathrm{m}$ or morules of 4 to $6 \mu \mathrm{m}$ size in the cytoplasm of blood neutrophils. Microscopically, morules could be registered for a short period of time, usually for 4 to 8 days (Egenvall et al., 1998).

\section{Epidemiology}

Granulocytic anaplasmosis in dogs is sporadically detected in different European countries: Sweden (Egenval et al., 1996, 1998); Norway (Ekerstad et al., 1996); Switzerland (Pusterla et al., 1997); Italy (Gravino et al., 1997); Austria (Kirtz., 2000); Great Britain (Bexfield., 2005); Slovenia (Tozon et al., 2003); Germany (Jensen et al., 2007); and Czech Republic (Melter et al., 2007). In the USA, the disease (neutrophilic ehrlichiosis) was detected for the first time in 1971 in a German shepherd dog from Arkansas (Ewing et al., 1997). In 1998 it was also studied in 6 dogs from North Carolina and Virginia (Golgman et al., 1998). The latest data showed a remarkable wide prevalence - it was found in all states except for Mississippi and Nebraska (Alleman, 2007). A. phagocytophilum was evidenced for the first time in Australia in 2001, whereas the first incidence in Canada was in 2005 (Lester et al., 2005). Granulocytic anaplasmosis is a vector borne disease. The commonest vector of $A$. phagocytophilum in Europe is the tick I. ricinus. In 1995 it was identified as a disease vector for the first time in Sweden (Johansson et al., 1995), and then in Switzerland (Pusterla et al., 1999). The vectors in America are the ticks I. scapularis and I. pasificus (Davoust and Wamsley, 2008).

A. phagocytophilum is characterized with a trans-stage transmission. An infection with $A$. phagocytophilum could occur through blood transfusion (Ewing et al., 1997). There is no sex-related predisposition in dogs with regard to granulocytic anaplasmosis. Pets are not a real source of infection for humans, but are sentinel animals. Such are also cats, among which the disease is also encountered. The seroprevalence in cats varies from $4.3 \%$ to $38 \%$ (Billeter et al., 2007).

\section{Clinical signs}

The symptoms of granulocytic ehrlichiosis are not specific - fever (up to $41^{\circ} \mathrm{C}$ ), anorexia, lethargy, depression, vomiting, diarrhea, polyarthritis, splenomegaly, lymphoadenopathy and anemia. There are cases of coinfections with Borrelia burgdorferi) Babesia spp. and the tick-borne encephalitis virus (Tarello, 2003). In experimental infection, the clinical manifestation is not significant (Cohn, 2003). The described haematological deviations in this disease are: leukopenia, rarely leukocytosis, normocytic normochromic anaemia, eosinopenia and mild thrombocytopenia. At the onset of disease, thrombocytopenia may be more prominent.

\section{Diagnosis}

The detection of $A$. phagocytophilum morules in granulocytes is a sufficient prerequisite to identify the disease (Pusterla et al. 1997). This is evidenced in $5 \%$ to $37 \%$ infected granulocytes in dogs with clinical signs of $A$. phagocytophilum infection. For a more reliable diagnosis however, the performance of additional analyses is 
advised (Sirigireddy and Ganta, 2005), such as indirect immunofluorescence, PCR and isolation. Until now, all isolated strains have been cultivated on the human cell line HL-60 (Goodman et al., 1996). Since 2006, the ELISA SNAP 4Dx test kit appeared on the market (IDEXX Laboratories, Westbrook, Maine, USA), that has a high sensitivity (99.4\%) and specificity (100\%). It detects IgM and IgG antibodies against $A$. phagocytophilum

\section{Treatment}

The most efficient anti-Anaplasmatic preparation is doxicyline at a daily dose of $10 \mathrm{mg} / \mathrm{kg}$ for 3 to 4 weeks (Alleman, 2007). The clinical effect is manifested within a week after the application. The premature discontinuation of the therapy could however result in A. phagocytophilum carrier stage.

\section{HEPATOZOONOSIS}

Hepatozoonosis is a tick-borne disease of wild and domestic carnivores (meat eating animals) caused by protozoan parasite, Hepatozoon canis that is transmitted by ticks, usually the brown dog tick, $R$. sanguineus. It mode of transmission is unusual; the tick picks up the organism from an infected host while biting the animal. An uninfected host gets the disease by eating the tick, not from being bitten by the tick. Because of the long prepatent period of the parasite, this disease is not developed soon after tickbites of particular tick season, but there is all possibilities of occurrence of the disease all year round.

The life cycle of the apicomplexan protozoon Hepatozoon canis in its natural hosts Rhipicephalus sanguineus (tick) and Canis familiaris (domestic dog) was studied in an experimental infection. Tick nymphs were fed on a naturally infected dog, or they were infected by percutaneous injection of blood. Dogs were inoculated by ingestion of adult ticks containing mature oocysts. Gamonts were in syzygy $24 \mathrm{hr}$ after percutaneous injection of ticks. Early oocysts were detected $96 \mathrm{hr}$ after nymph repletion, and mature oocysts in adult ticks were infective to dogs 40 days postmolt. Merogony was detected in dog bone marrow from 13 days postinoculation $(\mathrm{PI})$ and included meronts containing 20-30 micromerozoites, and a second type with 2-4 macromerozoites. Monozoic cysts were observed in the spleen in conjunction with merogony. Gamontogony with infection of leukocytes by micromerozoites occurred from 26 days $\mathrm{PI}$, and gamont parasitemia, which completed the life cycle, was detected 28 days $\mathrm{PI}$. The length of the life cycle from nymphal attachment to parasitemia in dogs was 81 days. Increased body temperatures were evident from 16 to 27 days $\mathrm{PI}$ and paralleled the time of intensive bone marrow merogony. Skeletal pain and recumbency were manifested in 2 dogs (Baneth et al., 2007).

\section{Epidemiology}

The $H$. canis among dogs is widespread. Its distribution corresponds to that of the vector tick $R$. sanguineus in continents/countries such as Africa, South Europe, South America and Asia, including the Middle East, the pacific and Indian Ocean islands (Craig, 1984; Craig, 1990; Grevery, 1993; Baneth, 2006).

The initial studies on the seroprevalence of H.canis in dogs showed high to low percentage of infection in different countries such as $36 \%$ in Portugal, $17.6 \%$ in Nigeria, $2.5 \%$ in India, $2.3 \%$ in Israel and $2.1 \%$ in Thailand (Gevrey, 1993). Because of its frequency of asymptomatic course, the determination of the extent and intensity of H.canis infection require systemic, direct and indirect studies of this parasite in dogs.

The prevalence of H.canis infection in the body of dogs in the different regions is also considerably varying. Circulating $H$. canis gamonts in blood have been detected in $39 \%$ of dogs, in the rural areas of Rio de Jaciro state in Brazil (O'Dwyer et al., 2001), in 22\% of dogs in Zaria, Nigeria (Ezekolli et al., 1983) and in $1.2 \%$ of dogs in Malaysia (Rajamanickam et al., 1983). Similar to other tick-borne diseases as ehrlichiosis, babesiosis, Lyme diseases etc, the contact with $H$. canis in endemic regions is much more frequent than the clinical incidence of illness. Most dogs infected with $H$. canis probably develop subclinical infections. Among the dogs surveyed for the presence of $\mathrm{H}$. canis antibodies in Israel by Baneth et al. (1997), 33\% were found seropositive but only 3\% had gamonts in the blood and $1 \%$ exhibited severe clinical signs of infection. The distribution of $H$. canis is closely related to that of the definitive tick host $-R$. sanguineus (Wenyon, 1931; Baneth et al., 2001). It is a three-host tick and is considered to be one of the most prevalent species worldwide (Wenyon, 1931), adaptable to different environmental conditions and found in warm and temperate region. $H$. canis has a transphasic (trans-stage) transmission from nymph to imago. Trans-ovarial transmission has not been observed. Experimentally, ticks could be infected by percutaneous injection of gamonts, containing blood (Baneth et al., 2001).

Most cases of $H$. canis infections are detected in hot seasons, when the activity of the vector is higher. However, illnesses were observed during the cold month too, most likely during persisting infection (Baneth and Weigler, 1997). The host range of $H$. canis in carnivores is not yet elucidated, except for the domestic dog.

\section{Transmission}

Transmission of $H$. canis takes place when dogs ingest ticks containing mature oocyst in the haemocoel. $R$. sanguineus nymphs acquire the infection after feeding on an infected dog. After trans stadial transmission, the tick's adult stage is infective to dogs through oral inoculation (Baneth et al., 2001, 2007). 


\section{Clinical signs}

The infection with $H$. canis in dogs could occur in three forms: subclinical, which is probably the commonest one; acute, developing about one week before the death, and chronic with phases of clinical expression and remission (Beaufils et al., 1988). The clinical signs are very various, but non-specific.

In several studies in dogs experimentally and spontaneously infected with $H$. canis, the most frequently observed clinical signs were anaemia, emaciation and intermittent fever (Baneth, 2006). On many occasions, cachexia, depression, muscle hyperaesthesia, purulent conjunctivitis and rhinitis were reported. Less frequently, diarrhea (often bloody), anorexia, paraparesis and paraparalysis were observed. The low parasitaemia with gamont in less than $5 \%$ of neutrophils is the most commonly encountered extent of infection. It is generally related to asymptomatic or mild illness. The severe clinical signs are characteristics for high parasitaemia reaching $100 \%$ and often are associated with marked leukocytosis (Baneth, 2006).

\section{Pathology}

The principal gross pathology in dogs infected with $H$. canis is cachexia. Muscle atrophy is most frequently and most visible in the temporal region. Also, anaemia, midly icteric mucous coats and slightly enlarged spleen and liver were observed. Congestive changes in the lungs and the gastric mucous coat, and pale kidneys are also communicated (Craig, 1984, 1990; Gevrey, 1993; Baneth, 2006).

Histologically, schizonts are observed in the skeletal and cardiac muscles, lymph nodes, the spleen, liver, kidneys etc. (Craig, 1984, 1990; Gevrey, 1993; Baneth, 2006). Two types of schizonts are detected: microschizonts containing micromerozoites that are larger and macroschizonts filled with macromerozoites. Microschizonts in the various organs are observed more frequently and at higher extent at the time of schizont formation reaction. However, at the time of merozoites release, an intensive cell response is detected, consisting of equal amounts of macrophages and neutrophils and a varying number of eosinophils.

\section{Diagnosis}

\section{Clinical}

Anaemia is the commonest, primary haematological sign observed in most cases (Baneth, 2006). Usually, it is normocytic, normochromic and regenerative in particular. The leukocyte counts are often within the normal range, when the parasitaemia is low and increase in highly parasitaemic animals (up to $150,000 / \mu \mathrm{l}$ ). One third of dogs, infected with $H$. canis exhibited thrombocytopaenia, but in some instances, it is connected to co-infections such as ehrlichiosis. The changes in some serum biochemical parameters are clearly manifested and include hyperglobulinaemia and hypoalbuminaemia, increased creatine kinase and alkaline phospatase activities (Baneth, 1997).

\section{Parasitological}

The microscopic detection of $H$. canis gamonts in blood smears stained according to Romanovski-Giemsa, Pappenheim or with Hemacolor is the commonest diagnostic approach to this infection. The protozoa concentration is directly related to the severity of the illness. Gamonts are oval shape with dimensions of 812/3-6 $\mu \mathrm{m}$ and are detected in the cytoplasm of neutrophils and rarely in that of monocytes (Baneth, 2006). Schizonts of $H$. canis could be observed in histological or touch impression preparations from lymph nodes, spleen, and bone marrow. Schizonts are round or oval, with a diameter of about $30 \mu \mathrm{m}$ and contain 2 or 4 macromerozoites or over 20 micromerozoites. Histologically, microschizonts with the so-called "wheel spoke" shape could be observed (Baneth, 2006).

\section{Serological}

For sero-diagnostic purposes, indirect immunofluorescent antibody test (IFAT) and ELISA are applied. Previously prepared antigen of $H$. canis gamonts is used. These assays are performed mainly in epidemiological studies (Baneth et al., 2002).

\section{Treatment}

The primary drug used nowadays in the treatment of canine $H$. canis, is combination therapy of imidocarb dipropionate and tetracycline hydrochloride has been shown to achieve clinical cure. It is administered at 5-6 $\mathrm{mg} / \mathrm{kg}$, subcutaneously or intramuscularly at 14-day interval until disappearance of gamonts in blood. However, because of very slow elimination of gamonts in the peripheral blood, in certain cases, imidocarb dipropionate have to be administered over eight week.

Apart from this, antiprotozoal regimen, supportive care with non-steroidal anti-inflammatory drugs is very important. Some dogs with undiagnosed hepatozoonosis may recover as a result of good care by owners (Ewing and Panciera, 2003).

\section{BABESIOSIS}

Babesiosis, a tick-borne protozoan disease of animals caused by the parasite of the genus Babesia is of 
worldwide importance infection in dogs. It may occur by tick transmission, direct transmission via blood transfer from dog bites, blood transfusion, or transplacental transmission. The most common mode of transmission is by tick bite, the Babesia canis uses the tick as a vector to reach host mammals. Once infected, the Babesia organisms multiply within the erythrocytes of the host (Irwin, 2005).

Canine babesiosis ranges in severity from relatively mild to fatal and haemolytic anemia is the main clinical sign. Many species of Babesia belonging to the two forms of Babesia (lager form $B$. canis measuring 3-5 $\mu \mathrm{m}$ and smaller form, $B$. gibsoni measuring 1-3 $\mu \mathrm{m}$ ) are pathogenic to the dog. The major $B$. canis are both host and vector specific; thus $B$. canis (subtype vogell) is found exclusively in the dog with the tick $R$. sanguineus as its major vector (Soulsby 1982). B. gibsoni occurs mainly in Asia, North America and North and East Africa (Taboada, 1998). The common brown dog tick, $R$. sanguineus is the most predominant dog ticks in Nigeria. It does not readily attack humans but usually prefers non-human hosts for completion of its development (Okoli et al., 2006).

Canine babesiosis is endemic in Nigeria and according to Dipeolu (1975), tick vectors of $B$. canis occur in large numbers in most parts of Nigeria. The prevalence of babesiosis varies from one part of the country to another as Oduye and Dipeolu (1976) noted from blood smears of 500 dogs in Ibadan, Nigeria, that $B$. canis accounted for $53 \%$ parasitemia. Odewunmi and Uzoukwu (1979) while investigating the prevalence of blood parasites in 116 dogs at Enugu found out that Babesia canis accounted for $55.1 \%$. B. canis can affect dogs of all ages, although young dogs are mostly affected (Lobetti, 1998).

\section{Etiology}

Babesia (Apicomplexa: Piroplasmida) species are ticktransmitted parasites infecting a wide range of wild and domestic vertebrate hosts (Kuttler, 1988). Traditionally, identification of species has been based on host specificity and morphology of the intraerythrocytic piroplasms. Based on these, canine babesiae have been originally recognised to belong to two distinct species, the large pyriform (4-5 $\mu \mathrm{m})$ Babesia canis and the small usually pleomorph (1-2.5 $\mu \mathrm{m})$ Babesia gibsoni. On the basis of differences in geographical distribution, vector specificity and antigenic properties (Uilenberg et al., 1989; Hauschild et al., 1995), $B$. canis has been subdivided into three subspecies, namely $B$. canis canis transmitted by $D$. reticulatus and $R$. sanguineus in Europe, B. canis vogeli transmitted by $R$. sanguineus in tropical and subtropical regions and $B$. canis rossi transmitted by Haemaphysalis leachi in South Africa. These subspecies also differ from each other in pathogenicity. B. canis rossi causes a frequently fatal infection in domestic dogs, even after treatment; $B$. canis vogeli causes a moderate often clinically unapparent infection; and $B$. canis canis infections result in a more variable pathogenicity intermediate between $B$. canis rossi and B. canis vogeli (Uilenberg et al., 1989). Genetic differences between these subspecies have also been proved by Zahler et al. (1998).

Some authors (Zahler et al., 2004) suggested and some others (Passos et al., 2005) even used the species level for these three subspecies. Baneth et al. (2004) described a fourth subspecies with unknown vector named $B$. canis presentii which has been detected in cats. Recently, a novel large Babesia sp. has been detected in an infected dog from North America by Birkenheuer et al. (2004) which either represents a new Babesia sp. or is one of the nearly 100 Babesia spp described for which no genetic data have been reported. Canine babesiosis caused by $B$. canis has been reported in several European countries, particularly in the Mediterranean region, where $R$. sanguineus and $D$. reticulatus are its vectors.

Cases of autochthonous large Babesia infections have been reported from Belgium, Croatia, France, Germany, Hungary, Italy, Poland, Slovenia, Spain and the Netherlands (Losson et al., 1999; Beugnet, 2002; Cacció et al., 2002; Duh et al., 2004). Recent studies using molecular methods showed that in France, Slovenia and Spain where these vector species coexist, both $B$. canis canis and $B$. canis vogeli could be detected (Cacciò et al., 2002; Criado-Fornelio et al., 2003; Duh et al., 2004).

\section{Epidemiology}

The distribution of canine Babesia parasites is worldwide and is dependent on the presence of the specific tick vector responsible for their transmission, such that the Babesia canis vogeli which is transmitted by Rhipicephalus sanguineus is seen in North Africa, South America, Southern and Eastern Africa, and European countries (Duh et al., 2004; Matjila et al., 2004; Oyamada et al., 2005; Eiras et al., 2008; M'ghirbi and Bouattour, 2008); Babesia canis rossi transmitted by Haemaphysalis elliptica (Apanaskevich et al., 2007) is seen in South Africa and Sudan (Oyamada et al., 2005; Matjila et al., 2008), whereas Babesia caniscanis transmitted by Dermacentor reticulatus is distributed mainly in Europe (Caccio et al., 2002; Duh et al., 2004; Solano-Gallego et al., 2008). Dermacentor reticulatus is an exophilic and ditropic tick found mainly in forests, but adapted to suburban habitats and is the major vector species of canine babesiosis in France (Bourdoiseau, 2006). The small Babesia (Babesia gibsoni, Babesia conradae and Babesia (Theileria) annae) which has three genetically distinct entities are found mainly in Asia Matjila et al., 2007). Babesia conradae has been shown to be closely related to piroplasm isolates from wildlife and humans and distributed around the California area of USA while Babesia (Theileria) annae is similar to Babesia microti and Theileria equi and occurs mainly in Spain. The vector for this emergent canine 
infection has not been described, although Ixodes hexagonus is suspected based on their presence upon dogs in North-West of Spain and the relative absence of other ticks (Dixit et al., 2010).

What the above information means is that the detection of a small piroplasm in the erythrocytes of dogs is not indicative of Babesia gibsoni, for the simple reason that the small piroplasms share similar morphology. Thus, $B$. gibsoni cannot unequivocally be differentiated from $B$. equi or $B$. microti based on size, shape or location in the erythrocytes (Conrad et al., 1992; Zahler et al., 2000).

\section{Clinicopathological findings}

The clinical and pathological presentation of canine babesiosis varies and is dependent on the species/subspecies responsible for the infection; however, the classical presentations often include: Thrombocytopenia, febrile syndrome (Fever, anorexia, depression, dehydration) and haemolytic syndrome (anaemia, bilirubinuria, haemolysis) in acute cases while the chronic form corresponds to prolonged convalescence characterized by depression (Solano-Gallego et al., 2008). In terms of severity of infections associated with the subspecies of $B$. canis, evidence shows that $B$. canis rossi is the most virulent with haemolytic and inflammatory responses (Reyers et al., 1998), B. canis canis shows a transient parasitaemia $(<1 \%)$ associated with congestion of internal organs (Schetters et al., 1997), whereas $B$. canis vogeli lead to a relatively mild infection, often without clinical signs or where present may not be homogenous (Caccio et al., 2002; Solano-Gallego et al., 2008). Infections due to $B$. gibsoni are usually associated with splenomegally, hepatomegally, haemolytic anaemia and severe thrombocytopenia. Clinical signs of $B$. conradae are similar to those of $B$. gibsoni, but $B$. conradae infection is more pathogenic with pronounced anaemia, higher parasitaemia and lymphadenopathy (Kjemtrup and Conrad, 2006). B. (Theileria) annae infection is characterized by severe regenerative anaemia and thrombocytopenia, azotemia is seen in many cases, while the presence of hyaline and granular casts in the urine of infected dogs is suggestive of renal involvement in the disease.

\section{Diagnosis}

Babesia infections are traditionally diagnosed based on the detection of the parasites in thin blood smears stained with Giemsa, Romanowsky and field stains under a microscope. The blood smears prepared from capillary blood and buffy coat readily reveals the parasites since the parasitized erythrocytes tend to sludge in the capillaries and also preferentially parasitize the reticulocytes over the mature red blood cell (Mattia et al., 1993; Bohm et al.,
2005). Identification of the parasites relies on the morphology of the intraerythrocytic forms using their size; however, this method is affected by its limited sensitivity and the subjectivity of the observer especially during asymptomatic and chronic infections when the parasitaemia is low and usually undetected by microscopy. Song et al. (2004), Fukata et al. (1996) and Yamasaki et al. (2008) have developed a flow cytometry to diagnose and evaluate the level of $B$. gibsoni parasitaemia in vivo and in vitro using a fluorescent nucleic acid stain SYTO16 which has been shown to be rapid and reliable. Other serological tests that have been used for the diagnosis of canine babesiosis are indirect fluorescent antibody technique (IFAT) and enzyme linked immunosorbent assay (ELISA) technique. However, these serological tests are known to show cross-reaction between different species of Babesia and do not differentiate acute from chronic infection thus making them non-specific (Irwin, 2007). Cross antigenicity seen in the $B$. canis subspecies is thought to be responsible for vaccine failures in the field as observed by Uilenberg et al. (1989) and Schetters et al. (1995), thus the possibility of developing potent vaccines against canine babesiosis will be dependent on the proper differentiation of the different subspecies. Polymerase chain reaction (PCR) with its several variations as a diagnostic tool for Babesia parasites has been evaluated and found suitable because of its sensitivity and specificity which is estimated to approach $100 \%$ (Jefferies et al., 2007b), and its ability to detect past, asymptomatic is and current infections (Birkenheuer et al., 2004; Song et al., 2004). This method lays emphasis on the amplification of the babesia DNA instead of the anti-babesial antibodies, thus making it a very reliable diagnostic tool in acute, per acute and chronic infections most especially in immuno compromised and young. It has also been found quite useful in epidemiological studies for the identification of new subspecies and for the differentiation of close and genetically distant Babesia species (Birkenheuer et al., 2001). Recent advances in molecular techniques have seen an avalanche of methods used to diagnose these parasites.

\section{Transmission}

Transmission of Babesia parasite to the canine host is by the bite of specific ixodid tick vectors of the genus Rhipicephalus (Rhipicephalus sanguineus), Haemaphysalis (Haemaphysalis leachi, H. bispinosa and $H$. longicornis) and Dermacentor (Dermacentor reticulatus). Thus the specie of Babesia prevalent in a particular area is influenced by the presence of the specific tick vector in that geographical area. Birkenheuer et al. (2004) have suggested a direct dog to dog transmission of $B$. gibsoni. They suspect that the parasite is transmitted through blood and saliva when an infected dog with oral abrasions bites a naïve dog during fights. This bite-blood- 
saliva transmitted $B$. gibsoni infection has been associated with breeds of dogs renowned for aggression, such as the American Staffordshire/Pit Bull terriers in the USA and the Tosa breed in Japan. Trans-placental transmission has been reported in puppies as young as 3 days old while experimental infection has led to stillbirths or death of puppies 6 weeks post-partum.

\section{Treatment}

Drugs that have been used for the treatment of canine babesiosis (Atavaquone, azithromycin, diminazene aceturate, phenamidine isethionate, pentamidine, parvaquone, niridazone and trypan blue) are known to be unable to completely eliminate the parasites and the disease, but can only reduce the severity of the clinical signs and the mortality (Birkenheuer et al. 1999). These drugs show varying degrees of success rates either alone or in combination in terms of eliminating the parasites or reducing the parasite load as was adduced by Birkenheuer et al. (1999) and Matjila et al. (2007). Although no known drug(s) has/have the capacity to treat infection due to Babesia canis, the report of Birkenheuer et al. (2004) showed that a combination of azithromycin and atovaquone therapy is able to treat Babesia gibsoni infections in dogs successfully without infected erythrocytes being seen in capillary blood smear. Also, blood from dogs with this combination therapy was shown to be negative on PCR assay for about 4 months. Although research has shown that treatment of canine babesiosis due to $B$. gibsoni with diminazene and or imidocarb is ineffective (Birkenheuer et al., 1999), it is imperative to state that Imidocarb has the capacity to stop the multiplication of the intraerythocytic parasites and also allow the persistence of several parasites in order to induce immunity and as such are desirable for the treatment of infection due to $B$. canis. Most if not all the babesiacidal drugs are toxic to the host and are used with the utmost caution. Toxicity with these drugs is expressed in form of CNS disorders (diminazene); vomiting, colic and diarrhea alongside hepatic, renal or vascular complications (imidocarb). Irrespective of the drug(s) used for the treatment of canine babesiosis, it is recommended that supportive therapy using intravenous fluids, corticosteroids and blood transfusion be used alongside (Brandao et al., 2003).

\section{GENERAL PREVENTION OF TICK- BORNE DISEASES IN DOGS}

1. Numerous products and medications to prevent ticks on dogs are available both over the counter and from veterinarians. Some veterinarians suggest tick collar and preventive vaccination. Although no method offers $100 \%$ protection (Baneth, 2006).

2. Stray dogs are especially vulnerable to tick-borne diseases because of time spent in tick infested environments. Owners should therefore be diligent about applying topical or systemic tick-control treatments before letting them out (Baneth, 2006).

3. Dogs should be checked for ticks daily; if ticks are found, consider taking them to a veterinary clinic where a veterinarian or technician can remove them safely and show the dog owners how the removal is been done. Prompt removal of ticks is very essential avoids infection with pathogens (Shaw et al., 2001).

4. Avoidance of tick bites is the most cornerstone of prevention. Protective clothing (e.g., long-sleeved shirts and trousers tucked into socks) and footwear should be used in tick habitats. Ticks may be more visible on light-colored apparel. Clothing can be impregnated with acaricides such as permethrin. Tick repellents such as DEET are also helpful, although it should be kept in mind that they are only effective for a short period against ticks. For example, most tick repellents last less than 2 hours against Amblyomma spp. ticks. Clothing should be removed and decontaminated immediately after leaving a tickinfested environment.

\section{CONCLUSION}

Tick-borne diseases (TBDs), including emerging and reemerging infectious diseases, are important threats to human and animal health worldwide. Indeed, the number of reported human and animal infectious cases of novel TBD agents has increased in recent decades. However, TBDs tend to be neglected, especially in resource limited countries that often have limited diagnostic capacity (Yonqin et al., 2018).

In a study conducted in India it was discovered that on microscopy examination, only Hepatozoon gamonts were observed in twelve out of 525 (2.3\%; $95 \% \mathrm{Cl}: 1.2,4)$ blood smears. Using polymerase chain reaction (PCR), a total of 261 from 525 dogs (49.7\%; 95\% Cl: $45.4,54.1)$ in this study were infected with one or more canine tick-borne pathogen. Hepatozoon canis (30\%; 95\% Cl: 26.0, 34.0) was the most common TBD pathogen found infecting dogs in India followed by Ehrlichia canis $(20.6 \%$; $95 \% \mathrm{Cl}: 17.2$, 24.3), Mycoplasma haemocanis (12.2\%; 95\% Cl: 9.5 , $15.3)$, Anaplasma platys $(6.5 \%$; $95 \% \mathrm{Cl}: 4.5,8.9)$, Babesia vogeli $(5.5 \%, 95 \% \mathrm{Cl}: 3.7,7.8)$ and Babesia gibsoni $(0.2 \%$, $95 \% \mathrm{Cl}: 0.01,1.06)$. Concurrent infection with more than one TBD pathogen occurred in 39\% of cases. Potential tick vectors, Rhipicephalus (most commonly) and/or Haemaphysalis ticks were found on 278 (53\%) of dogs examined (Abd Rani et al., 2011).

Thus, the urgent need for more work to be done in developing regions of the globe to curb the devastating menace of TBDs. A more robust Molecular approach is required for the diagnosis of the species responsible for the TBDs other than the present microscopic method of diagnosis. 


\section{CONFLICT OF INTEREST}

The authors declare that they have no conflict of interest.

\section{REFERENCES}

Abd Rani, P. A.M., Irwin, P.J., Coleman, G. T., Gatne, M., \& Traub, R. J. (2011). A survey of canine tick-borne diseases in India. Parasites and Vectors, 4: 141-148.

Aguiar, D.M., Cavalcante, G.T., Pinter, A., Gennari, S.M., Camargo, L.M., Labruna, M.B., (2007). Prevalence of Ehrlichia canis (Rickettsiales: anaplasmataceae) in dogs and Rhipicephalus sanguineus (Acari: ixodidae) ticks from Brazil. J. Med. Entomol. 44, 126-132.

Alleman, R., \& Wamsley, H. (2008). An update on anaplasmosis in dogs. Veterinary Medicine, Pp. 212-220.

Apanaskevich, D. A., Horak, I. G., \& Camica, J. L. (2007). Redescription of Haemaphysalis (Rhipistoma) elliptica (Kock, 1844), an old taxon of the Haemaphysalis (Rhipistoma) leachi group from East and Southern Africa, and of Haemaphysalis (Rhipistoma) leachi (Audouin, 1826) (Ixodida, Ixodidae). Onderstepoort Journal of Veterinary Research, 74, 181-208.

Apanaskevich, D. A., Horak, I. G., \& Camicas, J. L. (2007). Redescription of Haemaphysalis (Rhipistoma) elliptica (Koch, 1844), an old taxon of the Haemaphysalis (Rhipistoma) leachi group from East and southern Africa, and of Haemaphysalis (Rhipistoma) leachi (Audouin, 1826) (Ixodida, Ixodidae). Onderstepoort Journal of Veterinary Research, 74(3), 181208.

Aydin, M. F., Sevinc, F., \& Sevinc, M., (2015). Molecular detection and characterization of Hepatozoon spp. in dogs from the central part of Turkey. Ticks Tick Borne Diseases. 6, 388-392

Azzag, N., Peti, E., Gandoin, C., Bouillin, B., Ghalmi, F., Haddad, N., \& Boulois, H. J. (2015). Prevalence of selected vectorborne pathogens in stray and client-owned dogs from Algiers. Comparative, Immunology, Microbiology and Infectious Diseases, 38, 1-7.

Baneth, G. (2006). Hepatozoonosis In: Infectious diseases of the dog and cat. 3nd ed., C. E. Greene (ed.) W. B. Saunders, Philadelphia, Pensylvania. Pp. 698-705.

Baneth, G. A. D., Samish, M., Alekseev, E., Aroch, I., \& Shkap, V. (2001). Transmission of Hepatozoon canis to dogs by naturally-fed or percutaneously-injected Rhipicephalus sanguineus ticks. Journal of Parasitology, 87(3), 606-611.

Baneth, G., \& Vincent-Johnson, N., (2006). Hepatozoonosis. In: Greene, C.E. (Ed.), Infectious Diseases of the Dog and Cat, 3rd ed. Saunders, Philadelphia. Pp. 698-705.

Baneth, G., Barta, J. R., Shkap, V., Martin, D. S., Macintire, D. K., \& Vincent-Johnson, N. (2000). Genetic and antigenic evidence supports the separation of Hepatozoon canis and Hepatozoon americanum at the species level. Journal of Clinical Microbiology, 38(3), 1298-1301.

Baneth, G., Gonen, D., Strauss, A., \& Shkap, V. (2002). ELISA for Hepatozoon canis antibodies - evaluation of experimentally and naturally infected dogs. Veterinary Clinical Pathology, 31 , 202.

Baneth, G., Kenny, M. J., Tasker, S., Anug, Y., Shkap, V., Levy, A., \& Shaw, S. E. (2004). Infection with a proposed new subspecies of Babesia canis, Babesia canis subsp. presentii identified in the domestic cat. Journal of Clinical Microbiology, 42, 99-105.

Baneth, G., Mathew, J. S., Shkap, V., Macintire, D. K., Barta, J.
R., Ewing, S. A., (2003). Canine hepatozoonosis: two disease syndromes caused by separate Hepatozoon spp. Trends Parasitology, 19, 27-31.

Baneth, G., Samish, M., \& Shkap, V. (2007). Life cycle of Hepatozoon canis (Apicomplexa: Adeleorina: Hepatozoidae) in the tick Rhipicephalus sanguineus and domestic dog (Canis familiaris). Journal of Parasitology, 93(2), 283-299.

Beaufils, J. P., Martin, J., \& Granel, E. (1988). Hepatozoonose canine. 2-e partie: A propos de 28 cas. Pratique Medicale et Chirurgicale de l'Animal de Compagnie, 23(4), 281-293.

Beugnet, F. (2002). Guide to major vector-borne diseases. Merial S.A.S. p. 203.

Bexfield H., Villiers J., \& Herrtage E. (2005) Immunemediated haemolytic anaemia and thrombocytopenia associated with Anaplasma phagocytophilum in a dog. Journal of Small Animal Practice, 46, 543-548.

Billeter S., Spencer J., Griffin B., Dykstra C., \& Blagburn B. (2007). Prevalence of Anaplasma phagocytophilum in domestic felines in the United States. Veterinary Parasitology, 147, 194-198.

Birkenheuer, A. J., Levy, M. G., \& Savary, K. C., (1999). Babesia gibsoni infections in dogs from North Carolina. Journal of American Animal Hospital Assocation, 35, 125-128.

Birkenheuer, A. J., Neel, J., Ruslander, J., Levy, M. G., \& Breitschwerdt, E. B. (2004). Detection and molecular characterization of a novel Babesia species in a dog. Veterinary Parasitology, 124, 151-160.

Birkenheuer, A. J., Neel, J., Ruslander, J., Levy, M. G., \& Breitschwerdt, E. B. (2001). Detection and molecular characterization of a novel Babesia species in a dog. Veterinary Parasitology. 124:151-160.

Bohm, M., Leisewitz, A. L., Thompson, P. N., \& Schoeman, J. P. (2005). Capillary and venous Babesia canis rossi parasitaemia and their association with outcome of infection and circulatory compromise. Veterinary Parasitology, 141, 18-29.

Borjesson, D. (2000). Ehrlichiosis: new perspectives on pathogenesis and diagnosis. Proc 18th Am Coll. Vet. Int. Med. Meet., 574-577.

Bowman, D., Susan, E. L., Lorentzen, L., Shields, J., Sullivan, M. P., \& Carlin, E. P. (2009). Prevalence and geographic distribution of Dirofilaria immitis, Borrelia burgdorferi, Ehrlichia canis, and Anaplasma phagocytophilum in dogs in the United States: Results of a national clinic-based serologic survey. Veterinary Parasitology, 160, 138-148.

Brandao, L. P., Hagiwara, M. K., \& Myiashiro, S. I. (2003). Humoral immunity and reinfection resistance in dogs experimentally inoculated with Babesia canis and either treated or untreated with Imidocarb dipropionate. Veterinary Parasitology, 114, 253-265.

Cacciò, S. M., Antunovic, B., Moretti, A., Mangili, V., Marinculic, A., Baric, R. R., \& Slemenda, S.B., Pieniazek, N.J. (2002). Molecular characterisation of Babesia canis canis and Babesia canisvogeli from naturally infected European dogs. Veterinary Parasitology, 106, 285-292.

Choidioni, P. L., Conlon, C. P., Hutchinson, D. B., Farquhar, J. A., Hall, A. P., Peto, T. E., \& Birley, H. (1995). DNA in canine blood samples. Journal of Clinical Microbiology, 41, 41724177.

Cohn A. (2003). Ehrlichiosis and related infections. Veterinary Clinics: Small Animal Practice, 33, 863-884.

Conrad, P. A., Thomford, J. W., Marsh, A., Telford lii, S. R., Anderson, J. F., Spielman, A., Sabin, E. A., Yamane, I., \& Persing, D. H. (1992). Ribosomal DNA probe for differentiation of Babesia microti and Babesia gibsoni isolates. Journal of 
Clinical Microbiology, 30(5), 1210-1250.

Craig, T. M. (1990). Hepatozoonosis. In: Infectious diseases of the dog and cat. first ed., C. E. Greene (ed.) W. B. Saunders, Philadelphia, Pensylvania, Pp. 778-785.

Criado-Fornelio, A., Martinez-Marcos, A., Buling-Sarana, A., \& Barba-Carretero, J.C. (2003). Molecular studies on Babesia, Theileria and Hepatozoon in southern Europe Part I. Epizootiological aspects. Veterinay Parasitology, 113, 189201.

Criado-Fornelio, A., Martinez-Marcos, A., Buling-Sarana, A., \& Barba-Carretero, J. C. (2003). Molecular studies on Babesia, Theileria and Hepatozoon in southern Europe: Part II. Phylogenetic analysis and evolutionary history. Veterinary Parasitology, 114(3), 173-194.

Dantas-Torres, F., Chomel, B. B., Otranto, D. (2012). Ticks and tick-borne diseases: a One Health perspective. Trends Parasitology, 28, 437-446.

Dantas-Torres, F., Figueredo, L.A \& Brandao-Filho, S.P. (2006). Rhipicephalus sanguineus (Acari: Ixodidae), the brown dog tick, parasitizing humans in Brazil. Revista da Sociedade Brasileria de Medicana Tropical, 39, 64-67.

Davoust, B., \& Marie, J. (2007). Emergence of vector borne zoonoses: focus on granulocytic anaplasmosis (A.phagocytophilum), tick borne encephalitis, and a fleatransmitted rickettiossis (R.felis). Change and spatial shifts in Parasitic Diseases: Fact or Fiction? 21st International Conference of the WAAVP, Gent, Pp. 5-20.

Davoust, B., Bourry, O., Gomez, J., Lafay, L., Casali, F., Leroy, E., \& Parzy, D. (2006). Surveys on Seroprevalence of Canine Monocytic Ehrlichiosis among Dogs Living in the Ivory Coast and Gabon and Evaluation of a Quick Commercial Test Kit DotELISA. Annals of the New York Academy of Sciences, 1078(1), 464-469.

de la Fuente, J., Estrada-Pena, A., Venzal, J. M., Kocan, K. M., Sonenshine, D. E., (2008). Overview: ticks as vectors of pathogens that cause disease in humans and animals. Frontiers in Bioscience, 13, 6938-6946.

Dipeolu, O. O. (1975). A survey of the ectoparasitic infestations of dogs in Nigeria. Journal of small animal practice, 16(1-12), 123-129.

Dixit, P., Dixit, A. K., \& Varshney, J. P. (2010). Evidence of new pathogenic Theileria species in dogs. Journal of Parasitological Diseases, 34(1), 29-32.

Duh, D., Tozon, N., Petrovec, M., Strasek, K., \& Avsic-Zupanc, T. (2004). Canine babesiosis in Slovenia: Molecular evidence of Babesia canis canis and Babesia canis vogeli. Veterinary Research, 35, 363-368.

Dumler, J.S., Madigan, J.E., Pusterla, N. \& Bakken, J.S. (2007). Ehrlichioses in humans: Epidemiology, clinical presentation, diagnosis, and treatment. Clinical Infectious Diseases, 45 Suppl 1, S45-51.

Ekerstad, J., Blakstad, E., \& Artursson, K. (1996). Seroprevalens av Borrelia burgdor ferisensu lato og Ehrlichia sp. Hos hund fraet kystomrede I Aust-Agder. Norsk Veterinaertidsskritf, 108, 537-543.

Egenvall, E., Bjoersdorff, A., Lillihook, L., Olssonengvall, E., Karlstam, E., Artursson, K., Hedhammer, A., \& Gunnarsson, A. (1998). Early manifestations of granulocytic ehrlichiosis in dogs inoculated experimentally with a Swedish Ehrlichia species isolate. Veterinary Record, 143, 412-417.

Eiras, D. F., Basabe, J., Mesplet, M., \& Schnittger, L. (2008): First molecular characterization of Babesia canis vogeli in two naturally infected dogs of Buenos Aires, Argentina. Veterinary Parasitology, 157, 294-298.
Engvall, O., Petterson, B., Person, M., Artusson, K., \& Johansson, E. (1996). A 16S rRNA based PCR assay for detection and identification of granulocytic Ehrlichia species in dogs, horses, and cattle. Journal of Clinical Microbiology, 34, 2170-2174.

Ewing, S. A., Dawson, J. E., Panciera, R. J., Mathew, J. S., Pratt, K. W., Katavolos, P. \& Telford, S. R. (1997). Dogs infected with a human granulocytotropic Ehrlichia spp. (Rickettsiales: Ehrlichieae).Journal of Medical Entomology, 34, 710-718.

Ezekolli, C. D., Ogunkoya, A. B., Abdullahi, R., Tekedec, L. B., Sannusi, A., \& llemobade. A. A. (1983). Clinical and epidemiological studies on canine hepatozoonosis in Zaria, Nigeria. Journal of Small Animal Practice, 24, 455-460.

Farwell, G. E., LeGrand, E. K., \& Cobb, C. C. (1982). Clinical observations on Babesia gibsoni and Babesia canis infections in dogs. Journal of the American Veterinary Medical Association, 180(5), 507-511.

Fukata, T., Ohnishi, T., Okuda, S., Sasaki, K., Baba, E., \& Arakawa, A. (1996). Detection of canine erythrocytes infected with Babesia gibsoni by flow cytometry. Journal of Parasitology, 82, 641-642.

Gevrey, J. (1993). Hepatozoonose canine. Recueil de Medecine Veterinaire. 169 (5/6), 451-455.

Glaser, B. \& Gothe, R. (1998). Hundeturismus und -import: Eine Umfrage in Deutschland zu Ausmaß sowie Spektrum und Präferenz der Aufenthalts-, bzw. Herkunftsländer. Tierärztl. Prax. 26, 197-202.

Goldman, E. E., Breitschwerdt, E. B., Grindem, C. B., Hegarty, B. C., Walls, J. J., \& Dumler, J. S. (1998). Granulocytic ehrlichiosis in dogs from North Carolina and Virginia. Journal of Veterinary Internal Medicine, 12(2), 61-70.

Goodman, J., Nelson C., Vitale B., Madigan J., Dumler, J., Kurtti, T., Ulrike, G. \& Munderloh U. (1996). Direct Cultivation of the Causative Agent of Human Granulocytic Ehrlichiosis. New England Journal of Medicine, 335(5), 361.

Gothe, R. (1999). Rhipicephalus sanguineus (Ixodidae): Frequency of infestation and ehrlichial infections transmitted by this tick species in dogs in Germany; an epidemiological study and consideration. Wiener Tierarztliche Monatsschrift, 86(2), 49-56.

Gravino, A. E., De Capralis, D., Manna, L., Cerundolo, R., Sagazio, P., \& Buonavoglia, C. (1997).Preliminary report of infection in dogs related to Ehrlichia equi: description of three cases. New Microbiologica, 20, 361-363.

Groves, M. G., Dennis, G. L., Amyx, H. L., \& Huxsoll, D. L. (1975). Transmission of Ehrlichia canis to dogs by ticks (Rhipicephalus sanguineus). American Journal of Veterinary Research, 36(7), 937-940.

Harvey, J. W., Simpson, C. F., \& Gaskin, J. M. (1978). Cyclic thrombocytopenia induced by a Rickettsia-like agent in dogs. Journal of Infectious Diseases, 137(2), 182-188.

Hauschild, S., Shayan, P., \& Schein, E. (1995). Characterization and comparison of merozoite antigens of different Babesia canis isolates by serological and immunological investigations. Parasitological Research, 81, 638-642.

Hillyard, P. D. (1996). Ticks of North-West Europe. Synopses of the British Fauna (New series) No. 52 (ed. by Barnes, R. S. K. \& Crothers J. H.), Field Studies Council, Shrewsbury, 178p.

Homer, M. J., Aguilar-Delfin, I., Telford, S. R., Krause, P. J., \& Persing, D. H. (2000). Babesiosis. Clinical microbiology Reviews, 13(3), 451-469.

Inokuma, H., Ohno, K., \& Yamamoto, S. (1999). Serosurvey of Ehrlichia canis and Hepatozoon canis infection in dogs in Yamaguchi Prefecture, Japan. Journal of Veterinary Medical 
Science, 61(10), 1153-1155.

Inokuma, H., Oyamada, M., Davoust, B., Boni, M., Dereure, J., Bucheton, B., Hammad, A., Watanabe, M., Itamoto, K., Okuda, M., \& Brouqui, P. (2006). Epidemiological survey of Ehrlichia canis and related species infection in dogs in eastern Sudan. Annals of the New York Academy of Sciences, 1078(1), 461-463.

Inokuma, H., Oyamada, M., Kelly, P. J., Jacobson, L. A., Fournier, P. E., Itamoto, K., Okuda, M., \& Brouqui, P. (2005). Molecular detection of a new Anaplasma species closely related to Anaplasma phagocytophilum in canine blood from South Africa. Journal of Clinical Microbiology, 43(6), 29342937.

Irwin, P. (2007). Pups, PCRs and platelets: Ehrlichia and Anaplasma infections of dogs in Australia and overseas. Proceedings of the World Small Animal Veterinary Association Sydney, Australia.

Jefferies, R., Ryan, U. M., Muhlnickel, C. J., \& Irwin, P. J. (2003). Two species of canine Babesia in Australia: detection and characterization by PCR. Journal of Parasitology, 89(2), 409412.

Jensen, J., Simon, D., Escobar, H. M., Soller, J. T., Bullerdiek, J., Beelitz, P., Pfister, K., \& Nolte I. (2007). Anaplasma phagocytophilum in Dogs in Germany. Zoonoses Public Health, 54, 94-101.

Johansson, K. E., Petterson, B., Uhlen, M., Gunnarson, A., Malmquist, M., \& Olsson, E. (1995). Identification of the causative agent of granulocytic ehrlichiosis in Swedish dogs and horses by direct solid phase sequencing of PCR products from the 16S rRNA gene. Research in Veterinary Science, 58, 109-112.

Keefe, T. J., Holland, C. J., Salyer, P. E., \& Ristic, M. (1982). Distribution of Ehrlichia canis among military working dogs in the world and selected civilian dogs in the United States. Journal of America Veterinary Medical Association, 181, 236238.

Kelly, P. J., Eoghain, G. N., \& Raoult, D. (2004). Antibodies reactive with Bartonella henselae and Ehrlichia canis in dogs from the communal lands of Zimbabwe. Journal of the South African Veterinary Association, 75(3), 116-120.

Kenny, M. J., Shaw, S. E., Hillyard, P. D., \& Forbes, A. B. (2004). Ectoparasite and haemoparasite risks associated with imported exotic reptiles. Veterinary Record, 154, 434-435.

Kernif, T., Leulmi, H., Raoult, D., \& Parola, P. (2016). Emerging tick-borne bacterial pathogens. Microbiology spectrum, 4(3).

Kirtz, G., Leidinger, E., \& Moser, V. (2000). Canine granulocytare Ehrlichiose (CGE) bei einem Hund in Osterreich. Wiener Tierazliche Monatsschrift, 87, 241-246.

Kjemtrup, A. M., \& Conrad, P. A. (2006). A review of the small canine piroplasms from California: Babesia conradae in the literature. Veterinary Parasitology, 138,112-117.

Kuttler, K. L. (1988). World-wide impact of babesiosis. In: Babesiosis of domestic animals and man (ed. Ristic, M.). CRC Press, Boca Raton, FL, Pp. 1-22.

Labruna, M. B., \& Pereira, M.C. (2001). Carrapato em cães no Brasil. Clinical Veterinary, 30, 24-32.

Lester, S.J., Breitschwerdt, E. B., Collis, C. D., \& Hegarty, B. C. (2005). Anaplasmaphagocytophilum infection (granulocytic anaplasmosis) in a dog from Vancouver Island. Canadian Veterinary Journal, 46, 825-827.

Lillienook, I., Egenvall, A., \& Tvedten, H. (1998). Hematopathology in dogs experimentally infected with a Swedish granulocytic Ehrlichia species. Veterinary Clinical Pathology, 27, 116-122.
Lobetti, R. G. (1998). Canine Babesiosis. Compendium on Continuing Education for the Practicing Veterinarian, 20, 418431.

Losson, B., Mollet, J. J., Avez, F., Malaise, F., \& Mignon, B. (1999). Description of three cases of canine babesiosis in Belgium. Annales Medecine Veterinaire, 143, 119-122.

Mathew, J. S., Ewing, S. A., Panciera, R. J., \& Woods, J. P. (1998). Experimental transmission of Hepatozoon americanum Vincent-Johnson et al., 1997 to dogs by the Gulf Coast tick, Amblyomma maculatum Koch. Veterinary Parasitology, 80(1), 1-14.

Matjila, P. T., Leisewitz, A. L., Jongejan, F., \& Penzhorn, B. L. (2008). Molecular detection of tick-borne protozoal and ehrlichial infections in domestic dogs in South Africa. Veterinary Parasitology, 155, 152-157.

Matjila, P. T., Leisewitz, A. L., Jongejan, F., Penzhorn, B. L., (2008). Molecular detection of tick-borne protozoal and ehrlichial infections in domestic dogs in South Africa. Veterinary Parasitology, 155, 152-157

Melter, O., Stehlik, I., Kinska, H., Volfova, I., Ticha, V., \& Hulinska, D. (2007). Infection with Anaplasma phagocytophilum in a young dog: A case report. Veterinarni Medicina, 52(5), 207-212.

M'ghirbi, Y., \& Bouattour, A. (2008). Detection and molecular characterization of Babesia canis vogeli from naturally infected dogs and Rhipicephalus sanguineus ticks in Tunisia. Veterinary Parasitology, 152, 1-7.

Miller, W. W. (1908). Hepatozoon perniciosum n. g., n. sp., a haemogregarine pathogenic for white rats; with a brief description of the sexual cycle in the intermediate host, a mite (Laelaps echidninus Berlese). Bulletin of the Hygiene Laboratory of Washington, 46, 51-123.

Moreira, S. M., Bastos C. V., Araújo, R. B., \& Santos, M. (2003). Retrospective study (1998-2001) on canine ehrlichiosis in Belo Horizonte, MG, Brazil. Arquivo Brasilerio de. Medicina Veternaria e Zootecnis, 55, 141-147.

Murata, T., Inoue, M., Taura, Y., Nakama, S., Abe, H., \& Fujisaki, K., (1995). Detection of Hepatozoon canis oocyst from ticks collected from the infected dogs. Journal of Veterinary Medical Science, 57, 111-112.

Murphy, G. L., Ewing, S. A., Whitworth, L. C., Fox, J. C., \& Kocan, A. A. (1998). A molecular and serologic survey of Ehrlichia canis, E. chaffeensis, and E. ewingii in dogs and ticks from Oklahoma. Veterinary Parasitolology, 79, 325-339.

Ndip, L. M., Ndip, R. N., Esemu, S. N., Dickmu, V. L., Fokam, E. B., Walker, D. H., \& McBride, J. W. (2005). Ehrlichial infection in Cameroonian canines by Ehrlichia canis and Ehrlichia ewingii. Veterinary Microbiology, 111(1-2), 59-66.

Odewunmi, C. O., \& Uzoukwu, M. (1979). Survey of haemoprotozoan parasites of dogs in Enugu and Nsukka in Anambra State of Nigeria. Nigerian Veterinary Journal, 8(2), 46.

Oduye, C. O., \& Dipeolu, O. O. (1976). Blood Parasites of dogs in Ibadan-Nigeria. Journal of Small Animal Practice, 17(5), 331-334.

Okoli, I. C., Okoli, C. G., \& Opara, M. (2006). Environmental and multi-host Infestation of the brown dog tick, Rhipicephalus sanguineus in Owerri, South-East Nigeria. Veterinarski Arhive, 76(1), 93-100.

Otranto, D., Dantas-Torres, F., Giannelli, A., Latrofa, M.S., Cascio, A., Cazzin, S., Ravagnan, S., Montarsi, F., Zanzani, S. A., Manfredi, M. T., Capelli, G. (2014). Ticks infesting humans in Italy and associated pathogens. Parasites Vectors, 7, 328.

Oyamada, M., Davoust, B., Boni, M., Dereure, J., Bucheton, B., 
Hammad, A., Itamoto, K., Okuda, M. \& Inokuma, H. (2005): Detection of Babesia canisrossi, $B$. canis vogeli and Hepatozoon canis in dogs in a village of Eastern Sudan by using a screening PCR and sequencing methodologies. Clinical Diagnostic Laboratory Immunology, 12(1), 1343-1346.

Oyamada, M., Davoust, B., Boni, M., Dereure, J., Bucheton, B., Hammad, A., Itamoto, K., Okuda, M., Inokuma, H., (2005). Detection of Babesia canis rossi, B. canis vogeli, and Hepatozoon canis in dogs in a village of eastern Sudan by using a screening PCR and sequencing methodologies. Clinical Diagnostic Laboratory Immunology, 12, 1343-1346.

Parola, P., Davoust, B., \& Raoult, D. (2005). Tick-and flea-borne rickettsial emerging zoonoses. Veterinary Research, 36(3), 469-492.

Passos, L. M. F., Geiger, S. M., Ribeiro, M. F. B., Pfister, K., \& Zahler-Rinder, M. (2005). First molecular detection of Babesia vogeli in dogs from Brazil. Veterinary Parasitology, 127, 81-85.

Perez, M., Bodor. M., Zhang, C., \& Rikihisa, Y. (2005). Ehrlichia canis detection in symptomatic humans in Venezuela. In: Proceedings of the Fourth International Conference on Rickettsiae and Rickettsial Diseases, Logrono, Spain, 45.

Pusterla, N., Deplazes, P., Braun, U., \& Lutz, H. (1999). Serological evidence of infection with Ehrlichia spp. in red foxes (Vulpusvulpes) in Switzerland. Journal of Clinical Microbiology, 37, 1168-1169.

Pusterla, N., Huder, J., Leutenegger, C., Braun, U., Madigan, J. \& Lutz, H., (1999). Quantitative real-time PCR for detection of members of the Ehrlichiaphagocytophila genogroup in host animals and Ixodes ricinus ticks. Journal of Clinical Microbiology, 37, 1329-1331.

Pusterla, N., Huder, J., Wolfensberger, C., Litschi, B., Parvis, A. \& Lutz, H. J. (1997). Granulocytic ehrlichiosis in two dogs in Switzerland. Journal of Clinical Microbiology, 35, 2307-2309.

Qui, Y., Chiho, K., Masahiro, K., Saasa, N., Edgar, S., Walter, M.,, May, J. T., Mudenda, B. H., Ken, K., Ayato, T., Hirofumi, S., Martin, S., Ryo, N. (2018). Tick-borne haemoparasites and Anaplasmataceae in domestic dogs in Zambia. Ticks and Tickborne Diseases, 9, 988-995.

Reyers, F., Leisewitz, A. L., Lobetti, R. G., Milner, R. J., Jacobson, L. S., \& Van Zyl, M. (1998). Canine babesiosis in South Africa: more than one disease. Does this serve as a model for falciparum malaria? Annals of Tropical Medicine and Parasitology, 92(4), 503-511.

Rodriguez-Vivas, R. I., Albornoz, R. E. F., \& Bolio, G. M. E. (2005). Ehrlichia canis in dogs in Yucatan, Mexico: seroprevalence, prevalence of infection and associated factors. Veterinary Parasitology, 127(1), 75-79.

Schetters, T. P. M., Kleuskens, J. A. G. M., Scholtes, N. C., Van De Crommert, J., Krijnen, E., Moubri, K., Gorenflot, A., \& Vermeulen, A. N. (2006). Onset and duration of immunity against Babesia canisinfection in dogs vaccinated with antigen from culture supernatant. Veterinay Parasitology, 138, 140146.

Schnittger, L., Rodriguez, A. E., Florin-Christensen, M., \& Morrison, D. A. (2012). Babesia: a world emerging. Infection, Genetics and Evolution, 12(8), 1788-1809.

Shaw, S., Day, M., Birtles, R., \& Breitschwerdt, E. (2001). Tickborne infectious diseases of dogs. Trends in Parasitology, 17, 74-80.

Sirigireddy, K. R., \& Ganta, R. R. (2005). Multiplexdetection of Ehrlichia and Anaplasma species pathogens in peripheral blood byreal-time reverse transcriptase polymerase chain reaction. Journal of Molecular Diagnostics, 7, 308-316.

Smith, T. G. (1996). The genus Hepatozoon (Apicomplexa:
Adeleina). Journal of Parasitology, 82, 565-585

Soares, H. S., Marcili, A., Barbieri, A. R., Minervino, A. H., Moreira, T. R., Gennari, S. M., \& Labruna, M. B. (2017). Novel piroplasmid and Hepatozoon organisms infecting the wildlife of two regions of the Brazilian Amazon. International Journal for Parasitology: Parasites and Wildlife, 6(2), 115-121.

Solano-Gallego, L., \& Baneth, G. (2011). Babesiosis in dogs and cats-expanding parasitological and clinical spectra. Veterinary Parasitology, 181(1), 48-60.

Solano-Gallego, L., Trotta, M., Carli, E., Carcy, B., Caldin, M., \& Furlanello, T. (2008): Clinicopathological findings and DNA detection by means of PCR-RFLP in blood from Italian dogs suspected of tick-borne disease. Veterinary Parasitology, 157, 211-221.

Song, K. H., Kim, D. H., \& Hayasaki, M. (2004). The PCR-based detection of Babesia gibsoni infection in dogs (German shepherds) reared in South Korea. Annals of Tropical Medicine and Parasitology. 98(2), 149-153.

Soulsby, E. J. L. (1982). Helminths, Arthropods and protozoa of domesticated animals, 7th edition. Bailliere Tindall, London, UK. Pp. 717-723.

Stich R, Shaefer, J., Bremer, G., Needham, R., Jittapalapong, S. (2008). Host surveys, ixidid thick biology and transmission scenarios as related to the thick-borne pathogen, Ehrlichia canis. Veterinary Parasitology, 158, 256-273.

Stiles, J. (2000). Canine Rickettsial infections. Veterinary Clinics of North America Small Animal Practice, 30, 1135-1149.

Taboada, J. (1998). Babesiosis. In: infectious diseases of the dog and cat, 2nd edition, (Green CG, editor). WB Saunders, Philadelphia. Pp. 473-481.

Tarello, W. (2003). Canine granulocytic ehrlichiosis in Italy. Acta VeterinariaHungarica. 51:73-90.

Tozon, N., Petrovec, M., \& Zupanc, T. (2003). Clinical and Laboratory features of the first detected cases of $A$. Phagocytophila infections in dogs from Slovenia. Annals of New York Academy of Science, 990, 424-428.

Uilenberg, G., Franssen, F. F. J., Perie, M., \& Spanjer, A. A. M. (1989). Three groups of Babesia canis distinguished and a proposal for nomenclature. Veterinary Quarterly, 11, 33-40.

Watanabe, M., Okuda, M., Tsuji, H., \& Inokuma. (2004). Seroepidemiological study of canine Ehrlichia infections in Yamaguchi prefecture and surrounding areas of Japan. Veterinary Parasitology, 124(1-2), 101-107.

Wenyon, C. M. (1931). Experimental infection of dogs with Hepatozoon canis. Transaction of the Royal Society of Tropical Medicineand Hygiene, 25, 6.

Yabsley, M. J., McKibben, J., Macpherson, C. N., Cattan, P. F., Cherry, N. A., Hegarty, B. C., Breitschwerdt, E. B., O`Connor, T., Ramaswamy, R., Paterson, T., Perea, M. L., Ball, G., Friesen, S., Goedd, J., Henderson, B., \& Sylvester, W. (2008). Prevalence of Ehrlichia canis, Anaplasma platys, Babesia canis vogeli, Hepatozoon canis, Bartonella vinsoni berkhoffii, and Rickettsia spp. in dogs from Grenada. Veterinary Parasitology, 151, 279-285.

Yamasaki, M., Hwang, S., Ohta, H., Yamato, O., Maede, Y., \& Takiguchi, M. (2008). Flow cytometry to evaluate the level of Babesia gibsoni parasitaemia in vitro and in vivo by using the fluorescent nucleic acid stain SYTO16. Japanese Journal of Veterinary Research, 55(4), 129-136.

Yu, X. J., Liang, M. F., Zhang, S. Y., Liu, Y., Li, J. D., Sun, Y. L., Zhang, L., Zhang, $\quad$ Q. Popov, V. L., Li, C., Qu, J., Li, Q., Zhang, Y. P., Hai, R., Wu, W., Wang, Q., Zhan, F. X., Wang, X. J., Kan, B., Wang, S. W., Wan, K. L., Jing, H. Q., Lu, J. X., Yin, W. W., Zhou, H., Guan, 
X. H., Liu, J. F., Bi, Z. Q., Liu, G. H., Ren, J., Wang, H., Zhao, Z., Song, J. D., He, J. R., Wan, T., Zhang, J. S., Fu, X. P., Sun, L. N., Dong, X. P., Feng, Z. J., Yang, W.Z., Hong, T., Zhang, Y., Walker, D. H., Wang, Y., Li, D.X., (2011). Fever with thrombocytopenia associated with a novel bunyavirus in China. New England Journal of Medicine, 364, 1523-1532.

Zahler, M., Rinder, H., Schein, E., \& Gothe, R. (2000). Detection of a new pathogenic Babesia microtlike species in dogs. Veterinary Parasitology, 89, 241-248.
Zahler, M., Schein, E., Rinder, H., \& Gothe, R. (1998). Characteristic genotypes discriminate between Babesia canis isolates of differing vector specificity and pathogenicity to dogs. Parasitological Research, 84, 544-548. 